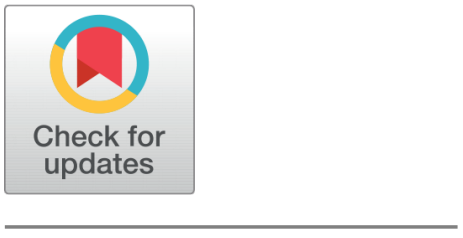

OPEN ACCESS

Received: 05.02.2021

Accepted: 08.04.2021

Published: 25.04 .2021

Citation: Matta S, Malga BS, Appidi L, Pramod Kumar P (2021) Chemical Reaction and Heat Source Effects on MHD Free Convective Flow over A Linearly Accelerated Moving Vertical Porous Plate. Indian Journal of Science and Technology 14(13): 1044-1055. https://doi.org/ 10.17485/IJST/v14i13.229

*orresponding author.

mswethamaths@gmail.com

Funding: None

Competing Interests: None

Copyright: @ 2021 Matta et al. This is an open access article distributed under the terms of the Creative Commons Attribution License, which permits unrestricted use, distribution, and reproduction in any medium, provided the original author and source are credited.

Published By Indian Society for Education and Environment (iSee)

ISSN

Print: 0974-6846

Electronic: 0974-5645

\section{Chemical Reaction and Heat Source Effects on MHD Free Convective Flow over A Linearly Accelerated Moving Vertical Porous Plate}

\author{
Sweta Matta ${ }^{1,2 *}$, Bala Siddulu Malga2 ${ }^{2}$ Lakshmi Appidi1,2, P Pramod Kumar 2,3 \\ 1 Department of Mathematics, CMR Technical Campus, Kandlakoya, 501401, Telangana, India \\ 2 Department of Mathematics, GITAM University, Hyderabad, 502329, Telangana, India \\ 3 Department of Mathematics, B V Raju Institute of Technology, Narsapur, 502313, \\ Telangana, India
}

\section{Abstract}

Objective: To make discussion on the chemical reaction and heat source effects on MHD flow on micro polar fluid along vertical porous plate. Method: The governing dimensionless equations are involved analytically by using finite element scheme. Findings: The effects of governing parameters on the flow variables are discussed quantitatively with the help of graphs for the flow field, temperature field, concentration field, skin friction and Nusselt number. Novelty: The accuracy of the problem has been verified by comparing with the previous published work and the agreement between the results is excellent, which established confidence in the numerical results reported in this study.

Keywords: Heat source parameter; Finite Element Method; MHD; chemical reaction parameter; viscous dissipation

\section{Introduction}

Theoretical study of magneto-hydrodynamics (MHD) flow problem plays with a chemical reaction is of huge number of applications to scientists, engineers. In a lot of chemical engineering process chemical reaction take place involving a distant mass and working fluid in that the plate was touching. This process takes place in several manufacturing applications like developed of food processing, glassware, ceramic objects and polymer production. Foreign mass possibly here moreover naturally or mixed through the water or air. The existence of a distant mass in water and air effects few types of the chemical reactions. Chemical technology improved with the study of chemical effect. Such as food processing, generating the electric power and polymer fabrication. Ali et al. ${ }^{(1)}$ examined the effects of Heat and Mass movement through free convection flow in a vertical plate. Reddy et al. ${ }^{(2)}$ analyzed the chemical reaction effects on MHD natural convection. Sehra et al. ${ }^{(3)}$ examined the Convection heat mass transfer over a vertical plate with chemical reaction. Nayak et al. ${ }^{(4)}$ consideredthe chemical reaction results on stretching sheet. Kumar et al. ${ }^{(5)}$ interpreted the thermal diffusion effects on MHD. Babu et al. ${ }^{(6)}$ analyzed the impacts of chemical reaction, diffusion 
thermo and radiation on unsteady natural convective flow past an inclined vertical plate under aligned magnetic field. Babu et al. ${ }^{(7)}$ considered the radiation and chemical reaction results on MHD free convention mass transfer fluid flow in a porous plate. Kumar et al. ${ }^{(8)}$ studied the suction special effects on accelerated vertical on permeable plate. Hoq et al. ${ }^{(9)}$ studied theerror analysis of heat conduction partial differential equations. Prasad et al. ${ }^{(10)}$ considered radiation, viscous dissipation effects on the heated vertical plate in permeable medium. Magala et al. ${ }^{(11)}$ has investigated dissipation effects on accelerated vertical plate through suction. Kandasamy et al. ${ }^{(12)}$ interpreted the effects of heat and mass transfer along a wedge with heat source and concentration in the presence of suction. Lakshmi et al. ${ }^{(13)}$ considered viscous dissipation effects on pours. Bhagya Lakshmi et al. ${ }^{(14)}$ has studied the MHD free convective flow of dissipative fluid past an exponentially accelerated vertical plate. Shehzad et al. ${ }^{(15)}$ studied the MHD flow medium. Pramod Kumar et al. ${ }^{(16)}$ reviewed induced magnetic field in the free convective Radiating Stream above Permeable Laminate. Ekakitie et al. ${ }^{(17)}$ interpreted the impact of chemical reaction and heat source on MHD free convection flow over an inclined porous Surface. Anupam et al. ${ }^{(18)}$ studied the radiation effects on stretching sheet. Chamkha et al. ${ }^{(19)}$ explained in a permeable medium. Sankar et al. ${ }^{(20)}$ explained the radiation impacts in the semi-infinite permeable plate. Sweta et al. ${ }^{(21)}$ analyzed fem of heat absorption effects on MHD Casson fluid flows above exponentially accelerate temperature through ramped surface concentration.

The objective of the present work is to study the chemical reaction and heat source effects on MHD flow on micro polar fluid along vertical porous plate. It has been noticed that the chemical reaction and heat source parameter had an effect on velocity profile, temperature profile, and concentration profile. The governing partial differential equations are solved by Galerkin Finite Element Method. We have extended the problem of Bhagya Lakshmi ${ }^{(14)}$ in the presence of chemical reaction, heat source parameter and the accuracy of present problem have been verified by comparing with theoretical solution of Bhagya Lakshmi ${ }^{(14)}$ through figures and the agreement between the results is excellent. This has established confidence in the numerical results reported in this paper.

\section{Mathematical Formulations}

The transitory magneto-hydrodynamic free convective flow of fluid over a growing accelerated plate with unstable temperature presented. Here $\mathrm{x}, \mathrm{y}$ - axis are taken as along the plate in vertically straight way and normal to the plate. The plate is considering bound less in $\mathrm{x}$-direction, all the flows quantity turn into self-similar missing from the leading edge. The total physical quantities turning into functions of $\mathrm{t}, \mathrm{y}$. By time $\mathrm{t}<=0$. Fluids are at equal to $\mathrm{t}$ and $\mathrm{C}$ less important than the constant wall temperature, concentration correspondingly. By $t>0$, the plate was growing accelerated through a velocity $=u$ exp (at) in its own plane and temperature of the plate, concentration are rising linearly with time- $t$. An unvarying magnetic playing field amount $\mathrm{H}$ is applying in the $y$-direction. Therefore the magnetic field and the velocity are taken by $\mathrm{H}=(0, \mathrm{H}), \mathrm{q}=(\mathrm{u}, \mathrm{v})$. The fluids electrically conducted the magnetic Reynolds number is to a great extent less than 1 and therefore induced magnetic field can be uncared for in comparison with applying magnetic field in the non appearance of input electric field. The heat because of viscous dissipation considered into an account below the above assumptions with Boussines mass, energy, momentum and species governing the free convection boundary layer flows over vertical plate can be studied as:

Continuity equation:

$$
\frac{\partial v^{\prime}}{\partial y^{\prime}}=0
$$

Momentum equation:

$$
\frac{\partial u^{\prime}}{\partial t^{\prime}}=g \beta\left(T^{\prime}-T_{\infty}^{\prime}\right)+g \beta^{*}\left(C^{\prime}-C_{\infty}^{\prime}\right)+v \frac{\partial^{2} u^{\prime}}{\partial y^{\prime 2}}-\frac{\sigma \mu_{e}^{2} H_{0}^{2}}{\rho} u^{\prime}
$$

The Energy equation:

$$
\rho_{c_{p}} \frac{\partial T^{\prime}}{\partial t^{\prime}}=K \frac{\partial^{2} T^{\prime}}{\partial y^{\prime 2}}+\mu\left(\frac{\partial u^{\prime}}{\partial y^{\prime}}\right)+\frac{S^{*}}{\rho C_{p}}\left(T-T_{\infty}\right)
$$

The Concentration equation:

$$
\frac{\partial C^{\prime}}{\partial t^{\prime}}=D \frac{\partial^{2} c^{\prime}}{\partial y^{\prime 2}}-K_{1}^{*} C^{*}
$$


Boundary conditions can be written in dimensional form as

$$
\begin{aligned}
& t^{\prime} \leq 0: u^{\prime}=0, T^{\prime}=T_{\infty 2}^{\prime} C^{\prime}=C_{\infty}^{\prime} ; \text { for all } y^{\prime} \\
& t^{\prime}>0: u^{\prime}=u_{0} \exp \left(a^{\prime} t^{\prime}\right) \\
& T^{\prime}=T_{\infty}^{\prime}+\left(T_{w}^{\prime}-T_{\infty}^{\prime}\right) A t^{\prime} \\
& C^{\prime}=C_{\infty}^{\prime}+\left(C_{w}^{\prime}-C_{\infty}^{\prime}\right) A t^{\prime} \text { at } y^{\prime}=0 \\
& \text { and } u^{\prime} \rightarrow 0, T^{\prime} \rightarrow T_{\infty}^{\prime}, c^{\prime} \rightarrow c_{\infty}^{\prime} \text { as } y^{\prime} \rightarrow \infty
\end{aligned}
$$

Where $\mathrm{A}=\frac{u^{2}{ }_{0}}{v}, T^{\prime}{ }_{w}$ and $C^{\prime}{ }_{w}$ are constants

Let us familiarize the subsequent dimensionless

$$
\begin{aligned}
& \mathrm{u}=\frac{u^{\prime}}{u_{0}}, t=\frac{t^{\prime} u^{2}{ }_{0}}{v}, y=\frac{y^{\prime} u_{0}}{v}, \theta=\frac{T^{\prime}-T_{\infty}^{\prime}}{T_{w}^{\prime}-T_{\infty}^{\prime}}, M=\frac{\sigma_{e}^{\mu H^{L \prime}}{ }_{0} v}{\rho u^{2}}, G r=\frac{g \beta v\left(T_{w}^{\prime}-T_{\infty}^{\prime}\right)}{u^{3}{ }_{0}}, \operatorname{Pr}=\frac{\mu c_{p}}{K}, K=\frac{K^{*} V_{0}^{2}}{v^{2}} \\
& E=\frac{u_{0}^{2}}{C_{p}\left(T_{w}^{\prime}-T_{\infty}^{\prime}\right)}, a=\frac{a^{\prime} v}{u_{0}^{2}}, \mathrm{Gc}=\frac{g \beta^{*} v\left(C_{w}^{\prime}-C_{\infty}^{\prime}\right)}{u^{3}{ }_{0}}, C=\frac{\left(C^{\prime}-C_{\infty}^{\prime}\right)}{\left(C_{w}^{\prime}-C_{\infty}^{\prime}\right)}, S C=\frac{v}{D^{\prime}} \mathrm{S}=\frac{S^{*} v}{\rho C_{p} V_{0}^{2}}
\end{aligned}
$$

Then the resultant non-dimensional equations are:

$$
\begin{gathered}
\frac{\partial u}{\partial t}=G r \theta+G c C+\frac{\partial^{2} u}{\partial y^{2}}-M u \\
\frac{\partial \theta}{\partial t}=\frac{1}{P r} \frac{\partial^{2} \theta}{\partial y^{2}}+E\left(\frac{\partial u}{\partial y}\right)^{2}+S \theta \\
\frac{\partial C}{\partial t}=\frac{1}{S c} \frac{\partial^{2} C}{\partial y^{2}}-K_{1} C
\end{gathered}
$$

Boundary conditions can be written in dimensionless form as

$$
\left.\begin{array}{l}
\mathrm{U}=0, \theta=0, \mathrm{C}=0, \forall \mathrm{y}, \mathrm{t} \leq 0 \\
\mathrm{u}=\exp (\text { at }), \theta=\mathrm{t}, \mathrm{C}=\mathrm{t} \text { at } \mathrm{y}=0 \\
\mathrm{u} \rightarrow 0, \theta \rightarrow 0, \mathrm{C} \rightarrow 0 \text { as } y \rightarrow \infty
\end{array}\right\} \forall \mathrm{t}>0
$$

\section{Method of Solution}

The finite element method (FEM) is employed to solve the transformed, coupled boundary value problem defined by Equations.

(7)-(9) under Eq.(10). The fundamental steps involved in finite-element analysis of a problem are as follows:

Step 1: Discretization of the fluid domain into finite elements

Step 2: Generation of element equations

Step 3: Assembly of element equations

Step 4: Imposition of boundary conditions

Step 5: Solution of assembled equations

Numerical study of a dissipative fluid flow

The variation formulation associated with Equations. (7) - (9) are joined with boundary conditions (10), we represent the velocities $\mathrm{u}$, temperature $\theta$ and concentration C. By applying the Galerkin finite element method for equation (7) over a typical two-nodded linear element $(e) \quad\left(y_{j} \leq y \leq y_{k}\right)$ is

$$
\begin{aligned}
& u=N . \varnothing, \text { where } N=\left[N_{j}, N_{k}\right], \quad \varnothing=\left[\begin{array}{l}
u_{j} \\
u_{k}
\end{array}\right], N_{j}=\frac{y_{k}-y}{l}, \quad N_{k}=\frac{y-y_{j}}{l}, l=y_{k}-y_{j}=h \\
& \int_{y_{j}}^{y_{k}} N^{T}\left[\frac{\partial^{2} u}{\partial y^{2}}-\frac{\partial u}{\partial t}-M u+G_{r} \theta+G_{c} C\right] d y
\end{aligned}
$$


We write the element equation for the elements $y_{i-1} \leq y \leq y_{i}$ and $y_{i} \leq y \leq y_{i+1}$. Assembling these element equations, where $r=\frac{k}{h^{2}}$ where $\mathrm{h}$ and $\mathrm{k}$ are the mesh sizes along $\mathrm{y}$ direction and time direction respectively. Index $\mathrm{i}, \mathrm{j}$ refers space and time respectively. The mesh system consists of $h=0.4$ for velocity profiles and concentration profiles and $\mathrm{k}=0.5 \mathrm{has}$ been considered for computations. In the above equations taking $\mathrm{i}=1(1) \mathrm{n}$ and using initial and boundary conditions (10), the following system of equation are obtained.

$A_{i} X_{i}=B_{i}, \quad i=1,2,3 \ldots$

Where $A_{i}$ 's are matrices of order $\mathrm{n}$ and $X_{i}$ and $B_{i}^{\prime} s$ are column matrices having $\mathrm{n}$-components. The solution of above system of equations are obtained using Thomas algorithm for velocity, angular velocity, temperature and concentration. In order to prove the convergence and stability of Galerkin finite element method, we are using $\mathrm{C}$ programming with slightly change of values $\mathrm{h}$ and $\mathrm{k}$, then no significant difference was observed in the values of velocity, angular velocity, temperature, concentration. Hence, the Galerkin finite element method is steady and convergent.

\section{Skin friction:}

$$
\tau=\frac{\partial u}{\partial y} \mid y=0=\frac{\left(U_{i+1}-U_{i}\right)}{h}
$$

Table 1. Skin friction variation

\begin{tabular}{|c|c|c|c|c|c|c|c|c|c|c|}
\hline M & $\mathrm{Gr}$ & Gc & $\operatorname{Pr}$ & Sc & $\mathrm{a}$ & $S$ & $\mathrm{E}$ & K1 & $\mathrm{t}$ & Skin friction \\
\hline 4 & 5 & 5 & 0.71 & 0.22 & 0.5 & 0.5 & 0.5 & 0.5 & 0.2 & 1.99328 \\
\hline 6 & 5 & 5 & 0.71 & 0.22 & 0.5 & 0.5 & 0.5 & 0.5 & 0.2 & 2.00754 \\
\hline 8 & 5 & 5 & 0.71 & 0.22 & 0.5 & 0.5 & 0.5 & 0.5 & 0.2 & 2.02190 \\
\hline 2 & 5 & 5 & 0.71 & 0.22 & 0.5 & 0.5 & 0.5 & 0.5 & 0.2 & 0.7457 \\
\hline 2 & 5 & 5 & 1.0 & 0.22 & 0.5 & 0.5 & 0.5 & 0.5 & 0.2 & 0.8456 \\
\hline 2 & 5 & 5 & 7.0 & 0.22 & 0.5 & 0.5 & 0.5 & 0.5 & 0.2 & 1.9312 \\
\hline 2 & 5 & 5 & 0.71 & 0.5 & 0.5 & 0.5 & 0.5 & 0.5 & 0.2 & 1.06449 \\
\hline 2 & 5 & 5 & 0.71 & 2.0 & 0.5 & 0.5 & 0.5 & 0.5 & 0.2 & 1.34124 \\
\hline 2 & 5 & 5 & 0.71 & 3.0 & 0.5 & 0.5 & 0.5 & 0.5 & 0.2 & 1.97356 \\
\hline 2 & 5 & 5 & 0.71 & 0.22 & 0.5 & 0.5 & 0.5 & 0.5 & 0.2 & 1.1051 \\
\hline 2 & 5 & 5 & 0.71 & 0.22 & 1.0 & 0.5 & 0.5 & 0.5 & 0.2 & 1.4678 \\
\hline 2 & 5 & 5 & 0.71 & 0.22 & 2.0 & 0.5 & 0.5 & 0.5 & 0.2 & 1.7856 \\
\hline 2 & 5 & 5 & 0.71 & 0.22 & 0.5 & 0.5 & 0.5 & 0.5 & 0.2 & 0.14901 \\
\hline 2 & 5 & 5 & 0.71 & 0.22 & 0.5 & 1.0 & 0.5 & 0.5 & 0.2 & 0.15634 \\
\hline 2 & 5 & 5 & 0.71 & 0.22 & 0.5 & 2.0 & 0.5 & 0.5 & 0.2 & 0.16787 \\
\hline 2 & 5 & 5 & 0.71 & 0.22 & 0.5 & 0.5 & 0.5 & 0.5 & 0.2 & 0.37851 \\
\hline 2 & 5 & 5 & 0.71 & 0.22 & 0.5 & 0.5 & 0.5 & 1.0 & 0.2 & 0.36234 \\
\hline 2 & 5 & 5 & 0.71 & 0.22 & 0.5 & 0.5 & 0.5 & 2.0 & 0.2 & 0.35781 \\
\hline 2 & 5 & 5 & 0.71 & 0.22 & 0.5 & 0.5 & 0.5 & 0.5 & 0.2 & 1.43456 \\
\hline 2 & 7 & 7 & 0.71 & 0.22 & 0.5 & 0.5 & 0.5 & 0.5 & 0.2 & 1.36853 \\
\hline 2 & 10 & 10 & 0.71 & 0.22 & 0.5 & 0.5 & 0.5 & 0.5 & 0.2 & 1.23456 \\
\hline 2 & 5 & 5 & 0.71 & 0.22 & 0.5 & 0.5 & 0.5 & 0.5 & 0.2 & 0.14321 \\
\hline 2 & 5 & 5 & 0.71 & 0.22 & 0.5 & 0.5 & 2.0 & 0.5 & 0.2 & 0.12348 \\
\hline
\end{tabular}

\section{Nusselt number:}

$$
\mathrm{Nu}=\frac{-\partial \theta}{\partial y} \mid y=0=\frac{\left(T_{i+1}-T_{i}\right)}{h}
$$


Table 2. Nusselt number

\begin{tabular}{llllll}
\hline $\mathrm{M}$ & $\mathrm{Pr}$ & $\mathrm{E}$ & $\mathrm{S}$ & $\mathrm{t}$ & $\mathrm{NU}$ \\
\hline 2 & 0.07 & 0.05 & 0.5 & 0.2 & 0.14065 \\
3 & 0.07 & 0.05 & 0.5 & 0.2 & 0.14114 \\
5 & 0.07 & 0.05 & 0.5 & 0.2 & 0.14209 \\
2 & 0.07 & 0.05 & 0.5 & 0.6 & 0.43462 \\
3 & 0.07 & 0.05 & 0.5 & 0.6 & 0.43536 \\
5 & 0.07 & 0.05 & 0.5 & 0.6 & 0.43677 \\
2 & 0.07 & 0.05 & 0.5 & 0.2 & 0.14901 \\
2 & 1.0 & 0.05 & 0.5 & 0.2 & 0.35726 \\
2 & 3.0 & 0.05 & 0.5 & 0.2 & 0.38420 \\
2 & 0.07 & 0.05 & 0.5 & 0.6 & 0.43536 \\
2 & 3.0 & 0.05 & 0.5 & 0.2 & 1.15277 \\
2 & 0.07 & 0.05 & 0.5 & 0.2 & 0.14901 \\
2 & 0.07 & 3.0 & 0.5 & 0.2 & 0.14653 \\
2 & 0.07 & 7.0 & 0.5 & 0.14317 \\
2 & 0.07 & 0.05 & 0.5 & 0.6 & 0.44710 \\
2 & 0.07 & 3.0 & 0.5 & 0.6 & 0.44340 \\
2 & 0.07 & 7.0 & 0.5 & 0.2 & 0.43838 \\
\hline
\end{tabular}

\section{Sherewood number:}

$$
\mathrm{Sh}==\frac{-\partial c}{\partial y} \mid y=0=\frac{\left(C_{i+1}-C_{i}\right)}{h}
$$

Table 3. Sherwood number variation

\begin{tabular}{llll}
\hline Sc & K1 & T & Sh \\
\hline 0.22 & 0.5 & 0.2 & 0.26167 \\
0.6 & 0.5 & 0.2 & 0.32474 \\
0.96 & 0.5 & 0.2 & 0.35716 \\
2.00 & 0.5 & 0.2 & 0.37851 \\
0.22 & 0.5 & 0.6 & 0.78501 \\
0.6 & 0.5 & 0.6 & 1.00599 \\
0.96 & 0.5 & 0.6 & 1.07148 \\
2.00 & 0.5 & 0.6 & 1.13554 \\
0.22 & 0.5 & 0.2 & 0.26167 \\
0.22 & 2.0 & 0.2 & 0,26372 \\
0.22 & 4.0 & 0.2 & 0.26642 \\
0.22 & 0.5 & 0.6 & 0.78501 \\
\hline
\end{tabular}

\section{Results and Discussion}

In order to obtain purpose of problem we calculate arithmetic solutions shown used for non-dimensional profiles we have plotted Schmidt number Sc $=0.22$, Eckert number E, Acceleration parameter (a), Mass Grashof number (Gc), Magnetic parameter $(\mathrm{M})$, Heat source parameter $(\mathrm{S})$, Chemical reaction parameter $(\mathrm{K} 1)$, Prandtl number $\operatorname{Pr}=0.71$, Thermal Grashof number $(\mathrm{Gr})$ and time $\mathrm{t}=0.2,0.6$. 
Figure 1 (a) showed the effects of Prandtl number (Pr). We noticed that effect of Pr velocity profiles are decreases. Since fluids having high viscosity then we observed that it move slowly.

Figure 2 (b) and Figure 1(b) showed that reaction of Eckert number (E) on the velocity fields, Temperature fields. Observed that, velocity profiles, Temperature profiles increases as E increases. The Eckert number effects on the flow of field are to improve energy, yielding a larger temperature and greater buoyancy force. The increases in the buoyancy force are because of increases in dissipation parameter to improve the velocity.

Figure $1(\mathrm{c})$ shown that the effects of acceleration parameter (a) taking place the velocity fields. We noticed that rises in acceleration parameter leads to rises in velocity profile.

Figure 1(d), Figure 1(e) shown that the effects of the mass Grashof (Gc), Grashof number (Gr) number on the velocity profiles. It is observed that greater cooling of the surface in Grashof number, mass Grashof number results raises in the velocity of air. It is due to the fact increase in the values of thermal Grashof number; mass Grashof number has the tendency to increase the thermal and mass buoyancy effect. This gives rise to an increase in the induced flow.

Figure 1(f) shows the effect of time $t$ on the velocity in cooling of the plate. It is obvious from the figure that the velocity increases with the increase of time $t$.

Figure 1(g) shown that magnetic parameter $(\mathrm{M})$ increases while decreasing in velocity profile. The presence of transverse magnetic field produces a resistive force on the fluid flow. This force is called the Lorentz force, which leads to slow down the motion of electrically conducting fluid.

Figure 1(h) and Figure 3 (a) observed that velocity fields and concentration fields are decreases while increasing in Chemical reaction parameter $\left(K_{1}\right)$.

Figure 2(2a) observed that temperature profiles are decreases while increasing in Prandtl number (Pr). Physically, it is possible because fluids with have high viscosity and hence move slowly.

Figure 1(i) and Figure 2(2.c) illustrate the effect of heat absorption S on temperature fields and velocity fields. We observed that velocity fields and temperature fields are increases with increasing in the source parameter. It is seen that heat absorption/heat generation tends to accelerate the motion of the fluid. The positive sign indicates the heat generation (heat source) whereas negative means heat absorption (heat sink). Heat source physically implies the generation of heat from the, which increases the temperature in the flow field. Therefore, as the heat source parameter increased, the temperature increases steeply. The influence of heat source parameter $S>0$ on velocity and temperature profiles is very much significantly related to the heat sink parameter $\mathrm{S}<0$. These results are clearly supported from the physical point of view.

Figure 3(3b) illustrates that the non-dimensional concentration fields for Schmidt number (Sc). A decrease in concentration with increasing Sc. Also it is noticed that the concentration boundary layer becomes thin as the Schmidt number increases.
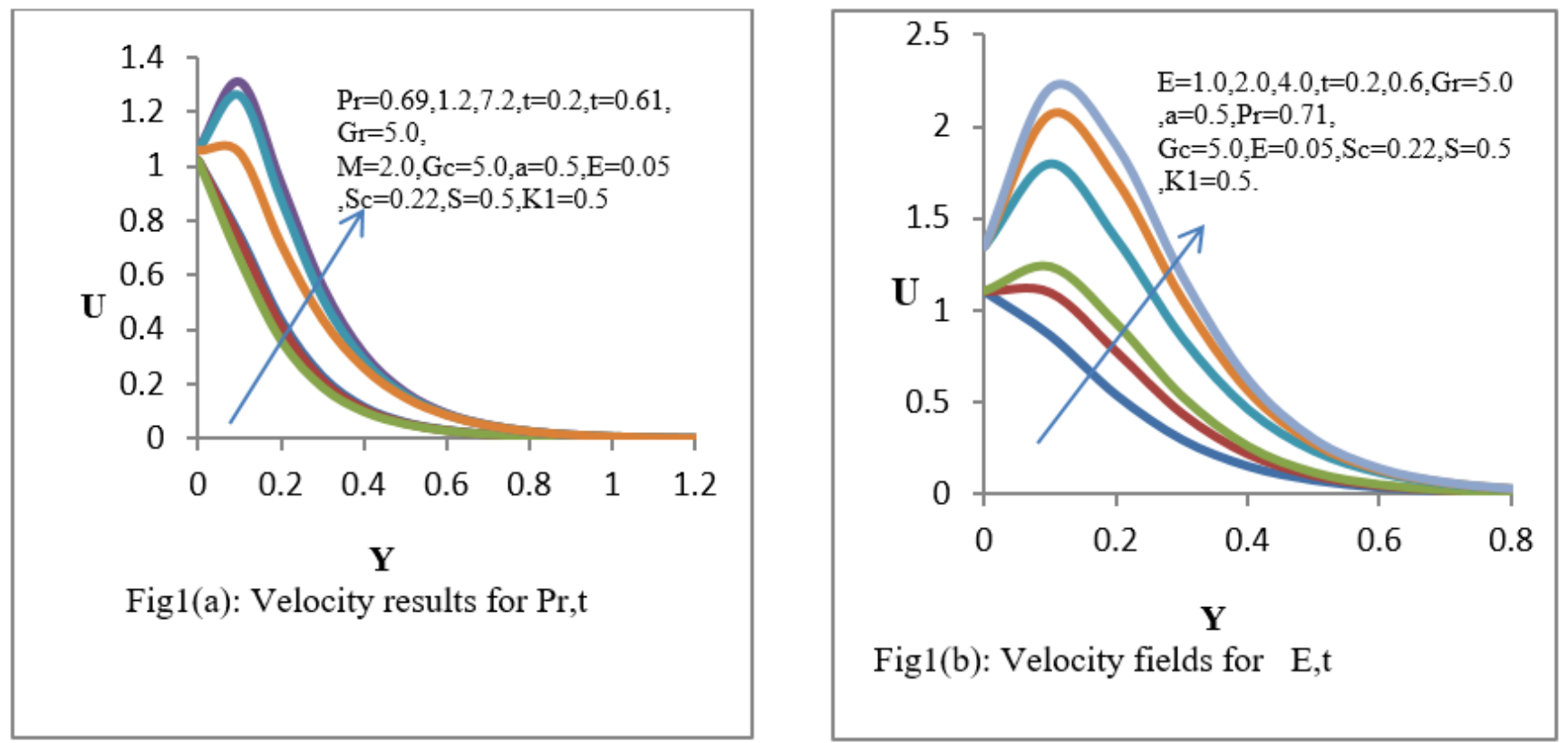

https://www.indjst.org/ 

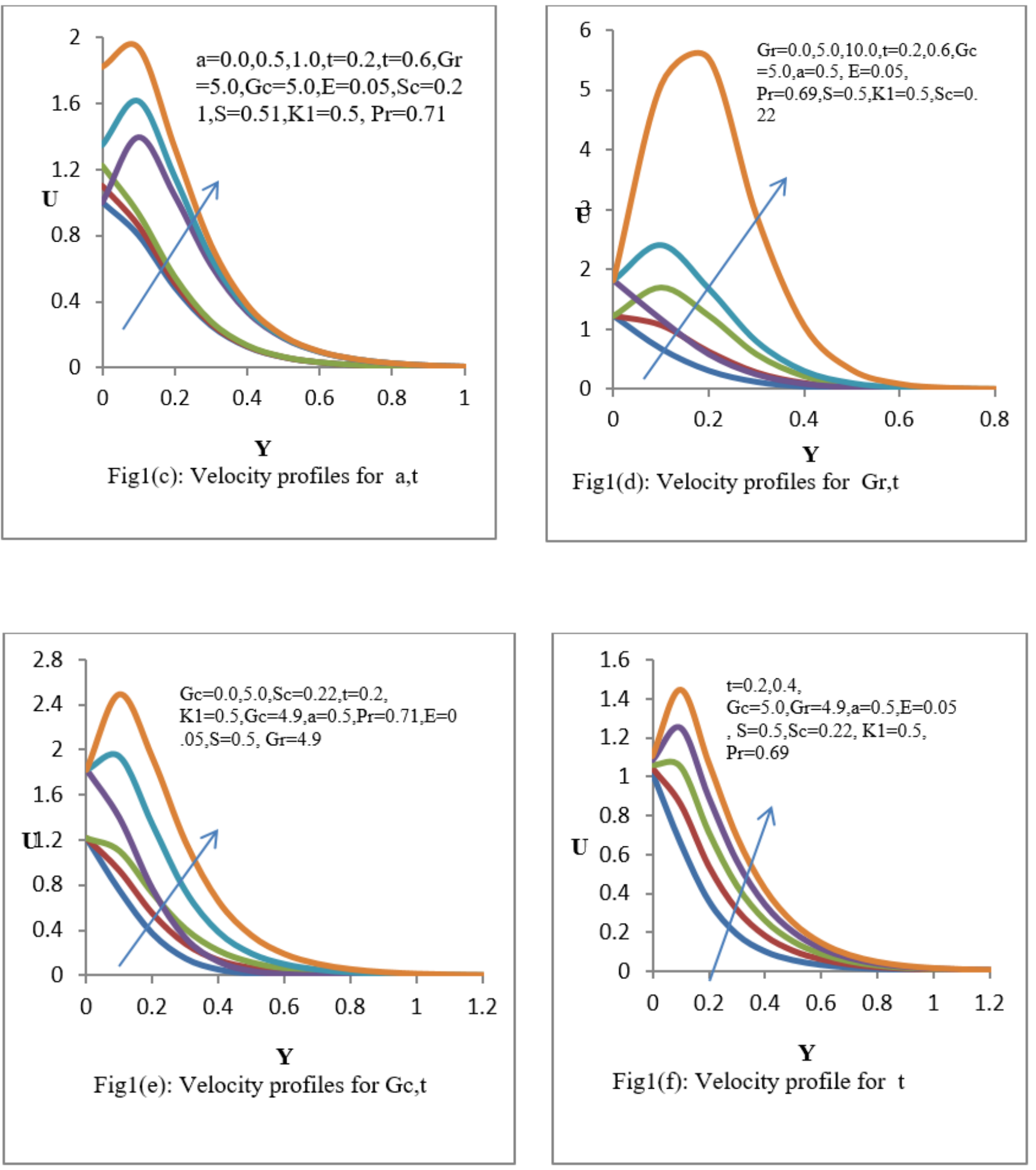


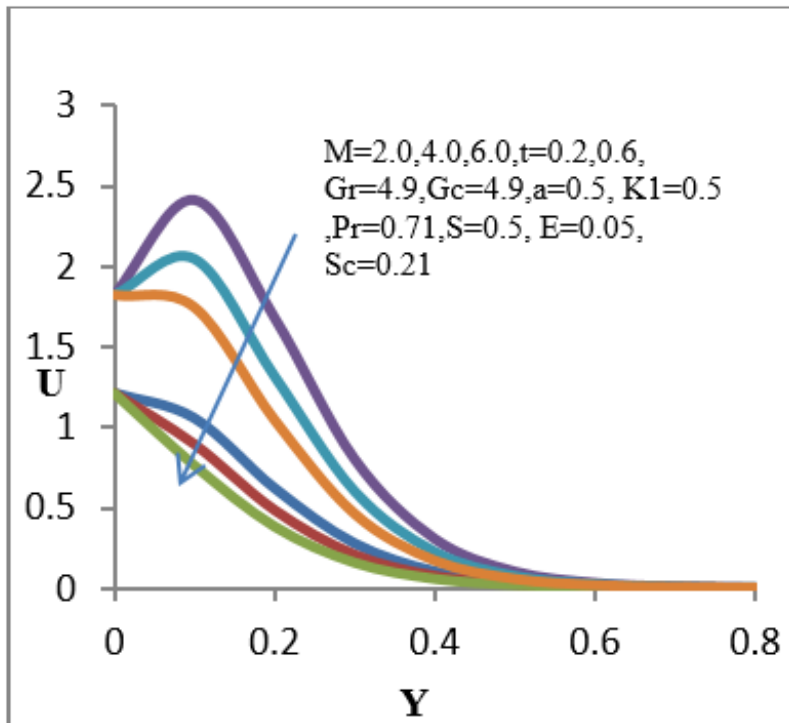

Fig1(g): Velocity profiles for $\mathrm{M}, \mathrm{t}$
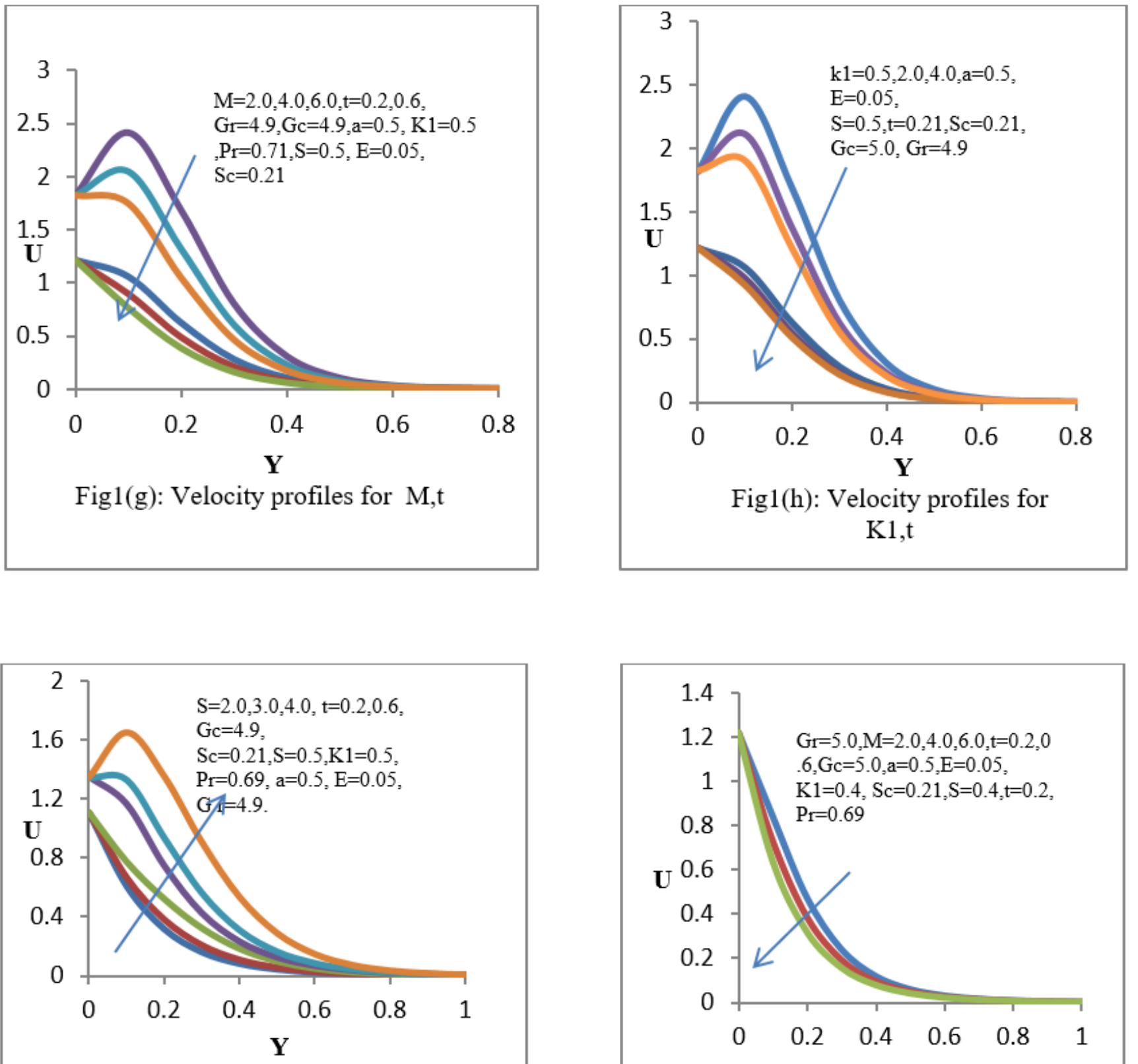

Fig1(i): Velocity profiles for S,t

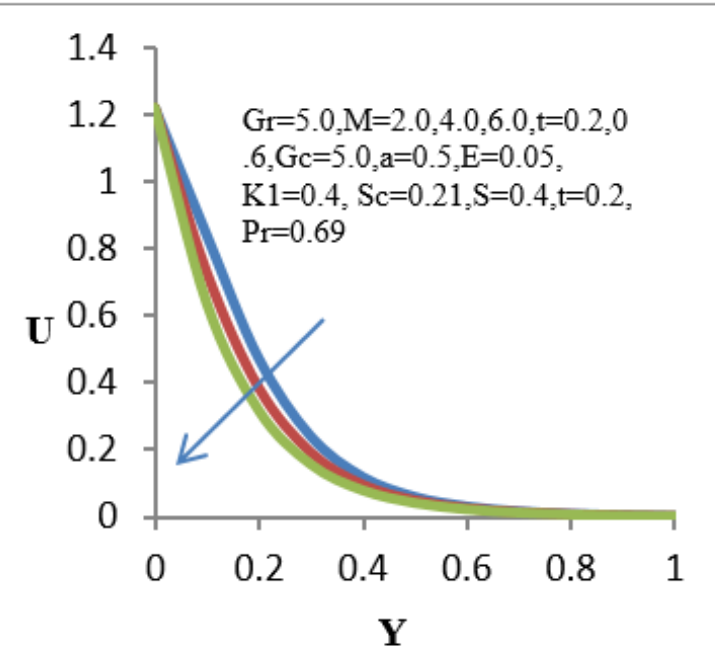

Fig1(j): Velocity profiles for $\mathrm{M}, \mathrm{t}$

Fig 1. 


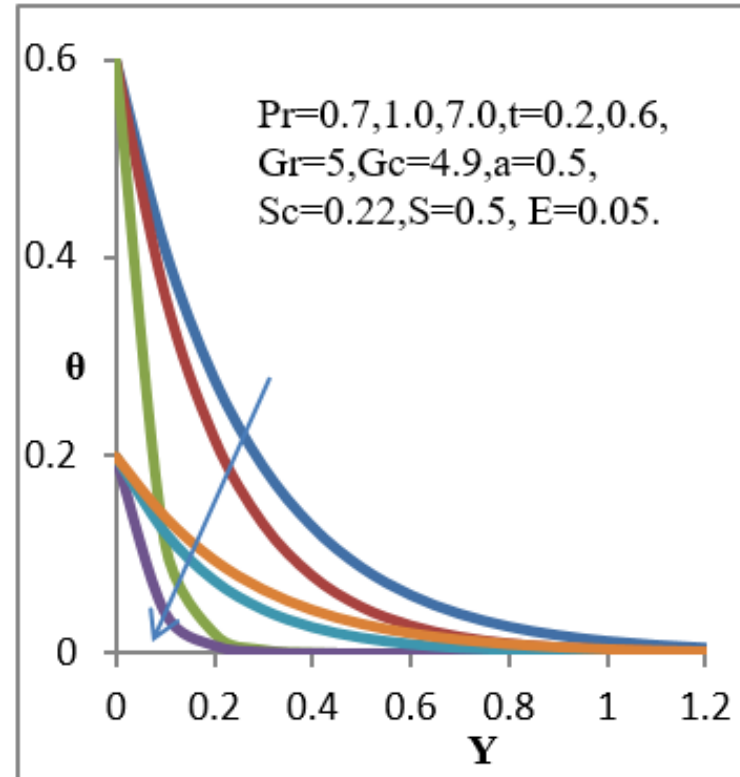

Fig2(a): Temparature profiles for $\operatorname{Pr}, \mathrm{t}$

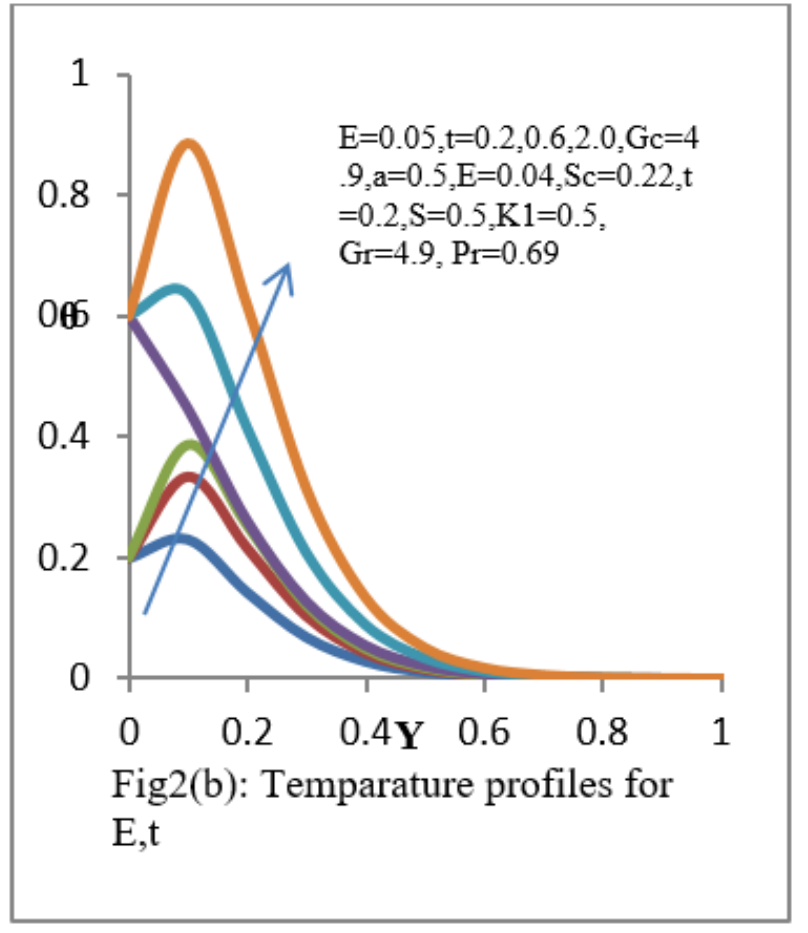

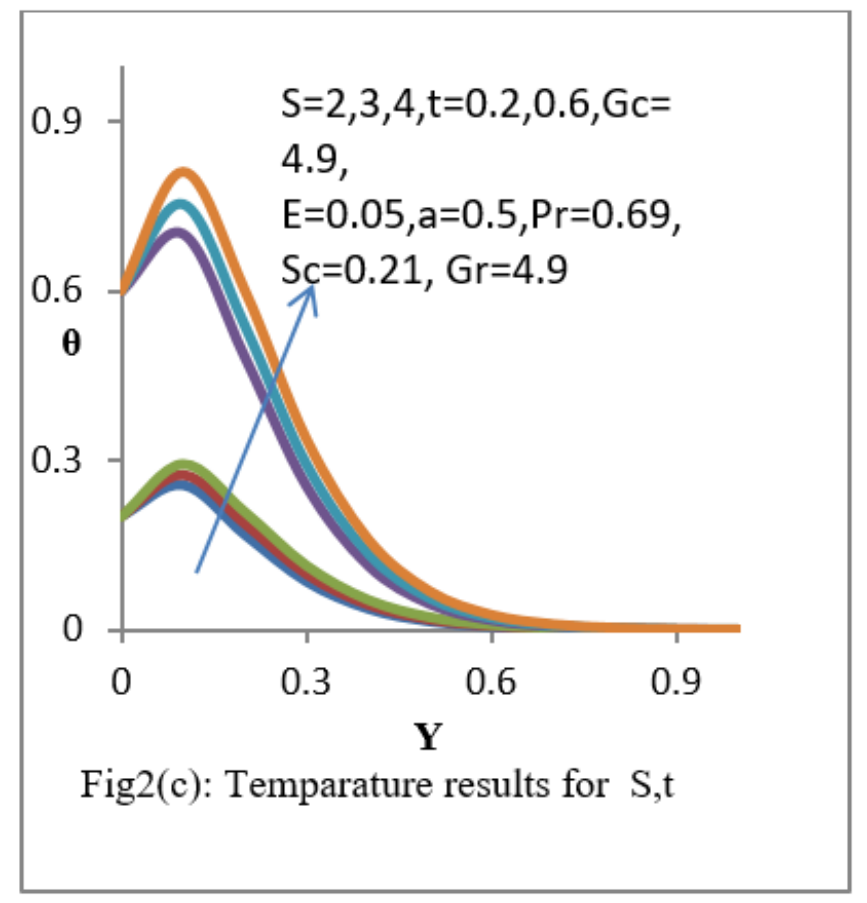

Fig 2. 

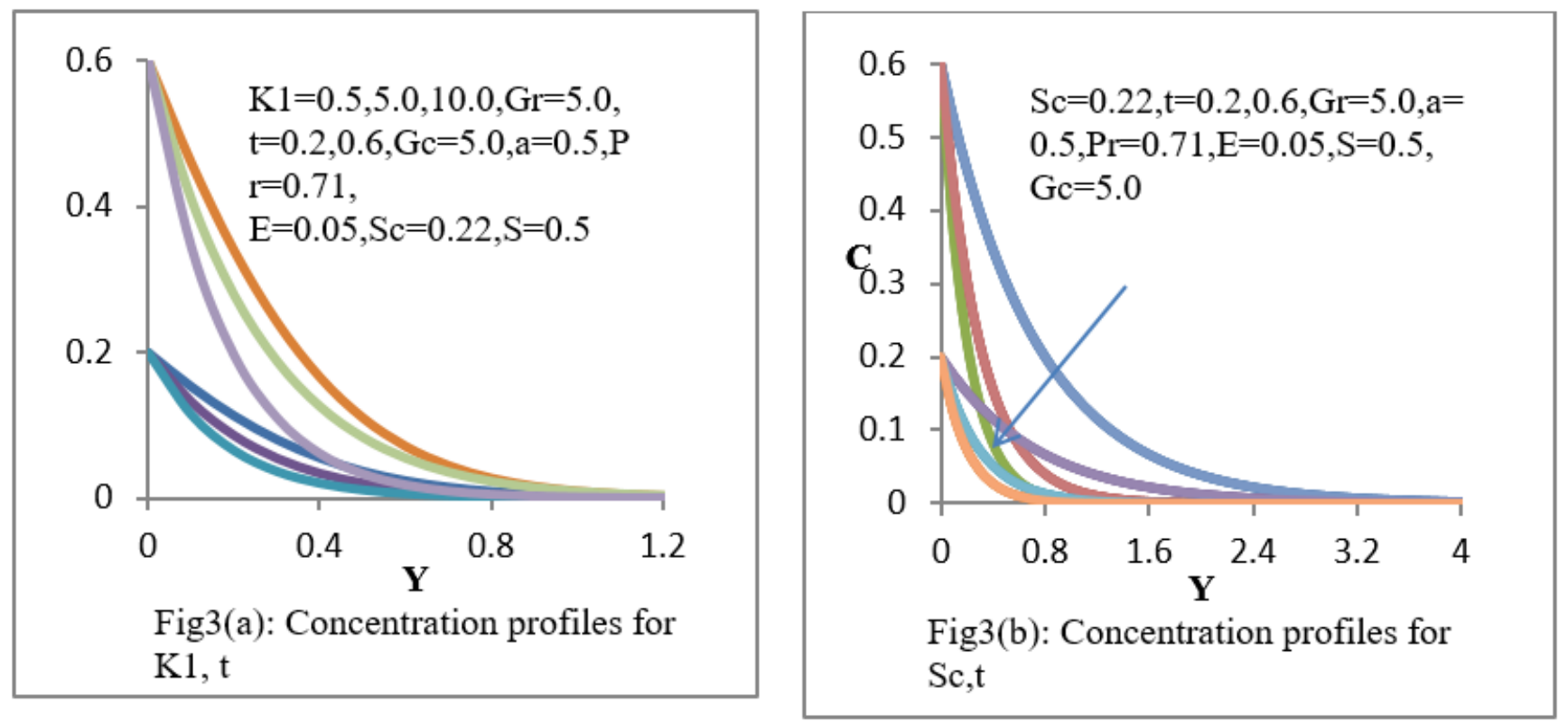

Fig 3.

\section{Conclusion}

The study on chemical reaction and heat source effects on the problem of Magneto hydrodynamics free convection of dissipative flow fluid past an exponentially accelerated plate. We studied velocity, concentration and temperature fields by different parameters like heat source parameter, Prandtl value, Schmidt number, modified Grashof and Grashof number, acceleration parameter, chemical reaction parameter. We observed that velocity fields decreases with respect to $t=0.2,0.6$ increases in magnetic parameter (M), Chemical reaction parameter K1, Modified Grashof number Gc, Prandtl number Pr, acceleration parameter a, Grashof number Gr. The following conclusions can be drawn

The velocity, temperature fields increases with increasing the heat source parameter.

1. The velocity flow of the fluid increases by means of increasing the viscous dissipation.

2. We observed those Schmidt number SC increases then the concentration profiles as decreases.

3. We observe that skin friction values are increases time $t$ by means of increasing in $\mathrm{M}, \mathrm{Sc}, \mathrm{Pr}, \mathrm{S}$ and a. While it decreases with an increase in thermal Gr, Gc and K1. Gr, Gc and k1 values are increases then skin friction values are decreases.

4. We noticed that M, Pr increases with increasing the Nusselt value. E,S are increases with decreasing in Nusselt value.

5. We noticed that K1, Sc values are increases with increasing the Sherewood number.

\section{Recommendation}

The same problem in future can be extended by Duffer effect

\section{Nomenclature}

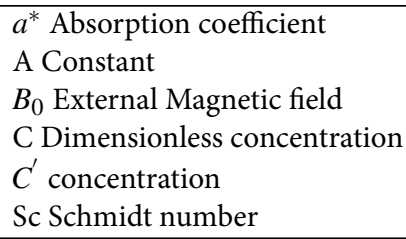




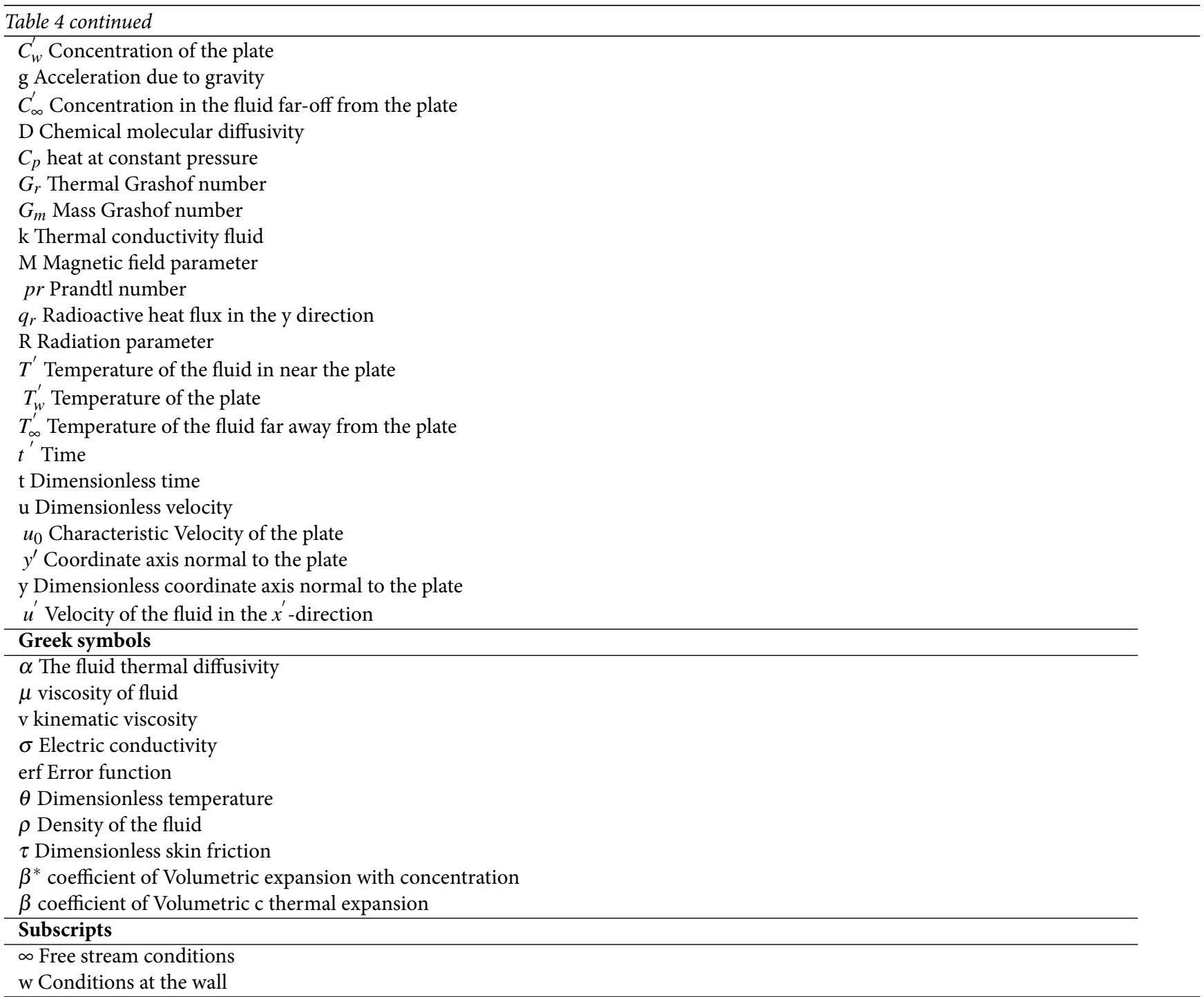

\section{References}

1) Ali F, Khan I, Shafie S, Musthapa N. Heat and Mass Transfer with Free Convection MHD Flow Past a Vertical Plate Embedded in a Porous Medium. Mathematical Problems in Engineering. 2013;2013:1-13. Available from: https://dx.doi.org/10.1155/2013/346281.

2) Reddy NN, Rao VS, Reddy BR. Chemical reaction impact on MHD natural convection flow through porous medium past an exponentially stretching sheet in presence of heat source/sink and viscous dissipation. Case Studies in Thermal Engineering. 2021;25:100879. doi:10.1016/j.csite.2021.100879.

3) Sehra, Haq SU, Shah SIA, Nisar KS, Jan SU, Khan I. Convection heat mass transfer and MHD flow over a vertical plate with chemical reaction, arbitrary shear stress and exponential heating. Scientific Reports. 2021;11(1):4265. Available from: https://dx.doi.org/10.1038/s41598-021-81615-8.

4) Nayak MK, Dash GC, Singh LP. Heat and mass transfereffects on MHD viscoelastic fluid over a stretching sheet through porous medium in presence of chemical reaction. Population and power research. 2016;5(1):70-80. Available from: https://doi.org/10.1016/j.jppr.2016.01.006.

5) Kumar P, Malga BS, Matta S, Appidi L. Effect of Viscous Dissipation on Unsteady MHD Free Convection Mass Transfer Flow of Polar Fluid over a Vertical Porous Plate in Presence of Thermal Diffusion and Heat source. International Journal of Advanced Science and Technology. 2020;29(5):10507-10519.

6) Ramakrishna SB, Thavada SK, Venkatachala GM, Bandaru M. Impacts of Chemical Reaction, Diffusion-Thermo and Radiation on Unsteady Natural Convective Flow past an Inclined Vertical Plate under Aligned Magnetic Field. Biointerface Research in applied Chemistry. 2021;11(5):13252-13267. Available from: https://doi.org/10.33263/BRIAC115.1325213267.

7) Matta S, Malga BS, Appidi L, Kumar PP. Radiation and chemical reaction effects on unsteady MHD free convention mass transfer fluid flow in a porous plate. Indian Journal of Science and Technology. 2021;14(8):707-717. Available from: https://dx.doi.org/10.17485/ijst/v14i8.20.

8) Kumar PP, Malga BS, Matta S, Appidi L. AIP Conference Proceedings. 2020. doi:10.1063/5.0014498.

9) Hoq SMA, Sulaeman E, Okhunov A. Error Analysis of Heat Conduction Partial Differential Equations using Galerkin's Finite Element Method. Indian Journal of Science and Technology. 2016;9(36):1-6. Available from: https://dx.doi.org/10.17485/ijst/2016/v9i36/102158. 
10) Prasad R, Reddy B. Radiation and mass transfer effects on an unsteady MHD free convection flow past a heated vertical plate in a porous medium with viscous dissipation. Theoretical and Applied Mechanics. 2007;34(2):135-160. Available from: https://dx.doi.org/10.2298/tam0702135p.

11) Malga BS, Kishan N. Finite element analysis for unsteady MHD heat and mass transfer free convection flow of polar fluids past a vertical moving porous plate in a porous medium with heat generation and thermal diffusion. Journal of Naval Architecture and Marine Engineering. 2014;11(1):69-82. Available from: https://dx.doi.org/10.3329/jname.v11i1.12844.

12) Kandasamy R, Periasamy K, Prabhu KKS. Effects of chemical reaction, heat and mass transfer along a wedge with heat source and concentration in the presence of suction or injection. International Journal of Heat and Mass Transfer. 2005;48(7):1388-1394. Available from: https://dx.doi.org/10.1016/j. ijheatmasstransfer.2004.10.008.

13) Appidi L, Malga BS, Matta S, Matta PP. Finite element analysis of viscous dissipation effects on unsteady free convention and mass transfer flow of fluid in a porous media with chemical reaction and heat source parameter. In: and others, editor. AIP Conference Proceedings;vol. 2246. 2020;p. 20089-20089. Available from: https://doi.org/10.1063/5.0014604.

14) Lakshmi KB, Raju GSS, Kishore PM, Rao NVRVP. Mhd free convective flow of Dissipative fluid Past an exponentially accelerated vertical plate. Int Journal of Engineering Research and Applications. 2013;3(6):689-702. Available from: http://www.ijera.com/papers/Vol3_issue6/DO36689702.pdf.

15) Shehzad SA, Hayat T, Alsaedi A. Three-dimensionalMHD flow of Casson fluid in porous medium with heatgeneration. J Appl Fluid Mech. 2016;9(1):215223. doi:10.18869/acadpub.jafm.68.224.24042.

16) Kumar P, Balasiddulumalga S, Matta L, Appidi. Heat Transfer Reaction on a Viscous Dissipative Free Convective Radiating Stream over a Permeable Laminate within Presence of Induced Magnetic Field. International Journal of Innovative Technology and Exploring Engineering. 2020;8(3):2057-2062. doi:10.35940/ijitee.C8887.019320.

17) Omamoke E, Emeka A. The Impact of Chemical Reaction and Heat source on MHD Free Convection Flow over an Inclined Porous Surface. International Journal of Scientific and Research Publications. 2020;10(05):9-17. Available from: https://dx.doi.org/10.29322/ijsrp.10.05.2020.p10103.

18) Bhandari A. Radiation and Chemical Reaction Effects on Nanofluid Flow Over a Stretching Sheet. Fluid Dynamics \& Materials Processing. 2019;15(5):557582. Available from: https://dx.doi.org/10.32604/fdmp.2019.04108.

19) Chamkha AJ, Khaled ARA. Hydromagnetic combined heat and mass transfer by natural convection from a permeable surface embedded in a fluidsaturated porous medium. International Journal of Numerical Methods for Heat \& Fluid Flow. 2000;10(5):455-477. Available from: https://dx.doi.org/10. $1108 / 09615530010338097$.

20) Reddy TS, Reddy M, Reddy NB. Unsteady MHD convective heat and mass transfer flow of micropolar fluid past a semi-infinite vertical moving porous plate in the presence radiation. Acta Ciencia Indica. 2008;34(3).

21) Matta S, Malga BS, Appidi L, Kumar PP. Finite element analysis of heat generation/absorption of Viscous Dissipation Effects on MHD Casson fluid flow over exponentially accelerated temperature with ramped surface concentration. AIP Conference Proceedings. 2020;p. 2269. doi:10.1063/5. 